\title{
Estimating technical efficiency of small scale beef cattle fattening in the lake zone in Tanzania
}

\author{
S. N. Mlote ${ }^{1 \star}$, N. S. Y. Mdoe ${ }^{2}$, A. C. Isinika ${ }^{3}$ and L. A. Mtenga ${ }^{4}$ \\ ${ }^{1}$ Ministry of Livestock and Fisheries Development, P. O. Box 9152, Dar es Salaam, Tanzania. \\ ${ }^{2}$ Department of Agricultural Economics and Agribusiness, Sokoine University of Agriculture, P. O. Box 3007, \\ Morogoro, Tanzania. \\ ${ }^{3}$ Institute of Continuing Education, Sokoine University of Agriculture, P. O. Box 3044, Morogoro, Tanzania. \\ ${ }^{4}$ Department of Animal Science and Production, Sokoine University of Agriculture, P. O. Box 3004, Morogoro, Tanzania.
}

Accepted 16 May, 2013

\begin{abstract}
This study examines the technical efficiency of small-scale beef cattle fattening in eight districts of Mwanza and Shinyanga regions, the lake zone in Tanzania. Data were collected using a structured questionnaire which was administered to $\mathbf{9 0}$ randomly selected cattle fatteners from the eight districts. Data were analyzed using descriptive methods and stochastic frontier production function approach. The estimated stochastic frontier production function showed that the herd size was the critical variable that affected weight gain in beef cattle fattening and hence beef output. The efficiency analysis results show that the estimated farm level technical efficiency ranged between 48 to $98 \%$ with a mean of $91 \%$, indicating that the majority of the beef cattle fattening operators in the study area are efficient though not at $100 \%$. The socio-economic determinants of the respondents' technical efficiency were age, education, experience, extension services and ethnicity. These findings can be used by the Ministry of Livestock and Fisheries Development extension agents to promote beef cattle fattening in areas where beef cattle fattening is not practiced in the country.
\end{abstract}

Key words: Average daily weight gain (ADG), cattle fattening operators, enterprises, technical efficiency, Tanzania shorthorn zebu (TSZ).

\section{INTRODUCTION}

The beef sub sector in Tanzania is dominated by indigenous cattle breeds which account for about 94 percent of the national cattle herd kept traditionally under pastoral and agro-pastoral production systems (Ministry of Livestock Development (MLD), 2006). The remaining $6 \%$, fall under improved dairy and beef cattle management systems. Indigenous cattle are made of Tanzania shorthorn zebu (TSZ) and boran and ankole [Ministry of Livestock and Fisheries Development (MLFD), 2011]. The Tanzania short horn zebu (TSZ) and ankole are the dominant indigenous breeds in the country.
These types are well known for their low genetic potential in terms of beef production (MLD, 2006). As a result, the contribution of livestock to the national economy as well as to the household's well-being is low. In 2010, for example the livestock sector contributed only 16 and $3.8 \%$ to the agricultural gross domestic product (AGDP) and national gross domestic products (NGDP), respectively and the sector grew by only $3.4 \%$ compared to $4.4 \%$ for the crop sector (United Republic of TanzaniaURT, 2011). There are two major factors contributing to this situation. First, low average meat production per head especially in the traditional beef production system 
where average cattle productivity is estimated to be 107 $\mathrm{kg}$ per head compared to the average of $166 \mathrm{~kg}$ per head for other developing countries and $198 \mathrm{~kg}$ per head for the world (FAOSTAT, 2005).

Second, the low rate of adoption of improved livestock production technologies such as use of artificial insemination to improve the size of animals and limited use of fattening technologies is another contributing factor (URT, 2011). Low productivity of beef cattle in addition with other factors such as low purchasing power for the most of the population in the country has prevented Tanzania from meeting the World Health Organization $(\mathrm{WHO})$ recommendation of a minimum per capital consumption of meat of $50 \mathrm{~kg}$ per year. The per capita consumption of meat in Tanzania is estimated to be $12 \mathrm{~kg}$, compared to the world average of $46.6 \mathrm{~kg} / \mathrm{year}$ (FAOSTAT, 2005; MLFD, 2012).

In order to improve the contribution of livestock to the national economy and well-being at the household level, the government has formulated the Livestock policy and strategy geared towards improving livestock productivity and commercialization of the livestock in the traditional sector (MLD, 2006, 2010, 2011). In the course of implementing the strategy, efforts have been made to encourage nomadic pastoralists with large cattle herds to reduce their herds and settle in areas where they are allocated land for cattle grazing. Besides encouraging pastoralists to settle, beef cattle fattening has been earmarked as one of the means to improve beef cattle productivity. Beef cattle fattening is a recent undertaking in the country, but it is increasingly gaining importance in some traditional livestock keeping regions of Tanzania. According to MLFD (2012), the number of fattened animals in the country is estimated to be 132,229 heads of cattle. Out of these, the lake zone (Mwanza, Shinyanga and Kagera regions) which is the study area account for $46.6 \%$. Beef cattle fattening has the potential to improve the Tanzanian economy, if well harnessed. However, this depends, to a large extent, on the efficiency of the production system, hence livestock productivity. Efficiency is concerned with relative performance of the processes used in transforming given input into output (Abu and Asember, 2011; Otieno et al., 2012). Efficiency measurement has received significant attention from researchers in different fields of study (Abu and Asember, 2011; Facayode et al., 2011; Dawing et al., 2011). Measuring efficiency is vital because it can guide resource utilization and may lead to considerable resource savings, which have important implication for both policy formulation and farm management (BravoUreta and Rieger, 1991). However, to date there is no study carried out to investigate the technical efficiency of beef cattle fattening enterprises undertaken in the country.

This study investigates the technical efficiency of beef cattle fattening enterprises practiced in Shinyanga and Mwanza regions of Tanzania. The specific objectives of the study are to: (i) estimate the technical efficiency of beef cattle fattening in the study area and (ii) examine the relationship between technical efficiency and sociocharacteristics of cattle fattening operators. Subsequent parts of the paper are organized into five main sections which include: the theoretical framework, methodological section, results and discussion, conclusion and recommendations.

\section{Theoretical framework}

Economic theory identifies three important efficiency measures (Boris et al., 1997; Effiong and Onyenweaku, 2006). These include; the allocative, economic and technical efficiency. The allocative efficiency (AE) reflects the ability of the farm to use the inputs in optimum proportions given their respective prices and the production technology. Economic efficiency (EE) is defined as the capacity of a firm to produce a predetermined quantity of output at minimum cost for a given level of technology. Technical efficiency (TE) is the measure of the farms success in producing maximum output from a given set of inputs. Alternatively, it is the ability to operate on the production frontier or the isoquant frontier (Effiong and Onyenweaku, 2006). This study examines the TE for beef cattle fattening operators in the study area.

\section{METHODOLOGY}

\section{Sampling and data collection}

Data for this study were collected from beef cattle fattening enterprises in Mwanza and Shinyanga regions in the lake zone in Tanzania. Geographically, Mwanza and Shinyanga regions lie in the Northern part of the country.

The sampling frame included all beef cattle operators who are engaged in beef cattle fattening in selected districts of Magu, Nyamagana and Sengerema in Mwanza region and Kahama, Kishapu, Meatu, Bariadi and Maswa districts in Shinyanga region as shown in Figure 1. The list of beef cattle fattening entrepreneurs was collected from the respective local government authority offices in the districts, from which 90 respondents were randomly selected. Global positioning system (GPS) devices were used to georeference all points where the interview were held.

Data were collected through face to face interviews conducted by the principal researcher during the dry season between July and September, 2011, with the assistance of local experienced interviewers who were adequately trained prior to the surveys. The data were collected during dry season because this is when fattening is practiced. During the wet season animals are able to get enough forage from the rangelands and are normally in good condition hence hardly any fattening was done. Data gathered include information on socio-economic variables of the entrepreneurs such as age, education, household size, location, experience, access to credit and extension services. Information was also collected on the inputs as well as output in terms of weight gain for fattened beef cattle. The inputs data collected included; feeds used, amount of minerals used, and treatment/drugs used while output data collected was the weight of beef cattle after the fattening period.

It was observed during the field survey that beef cattle fattening operators did not weigh their animals before and after fattening. 


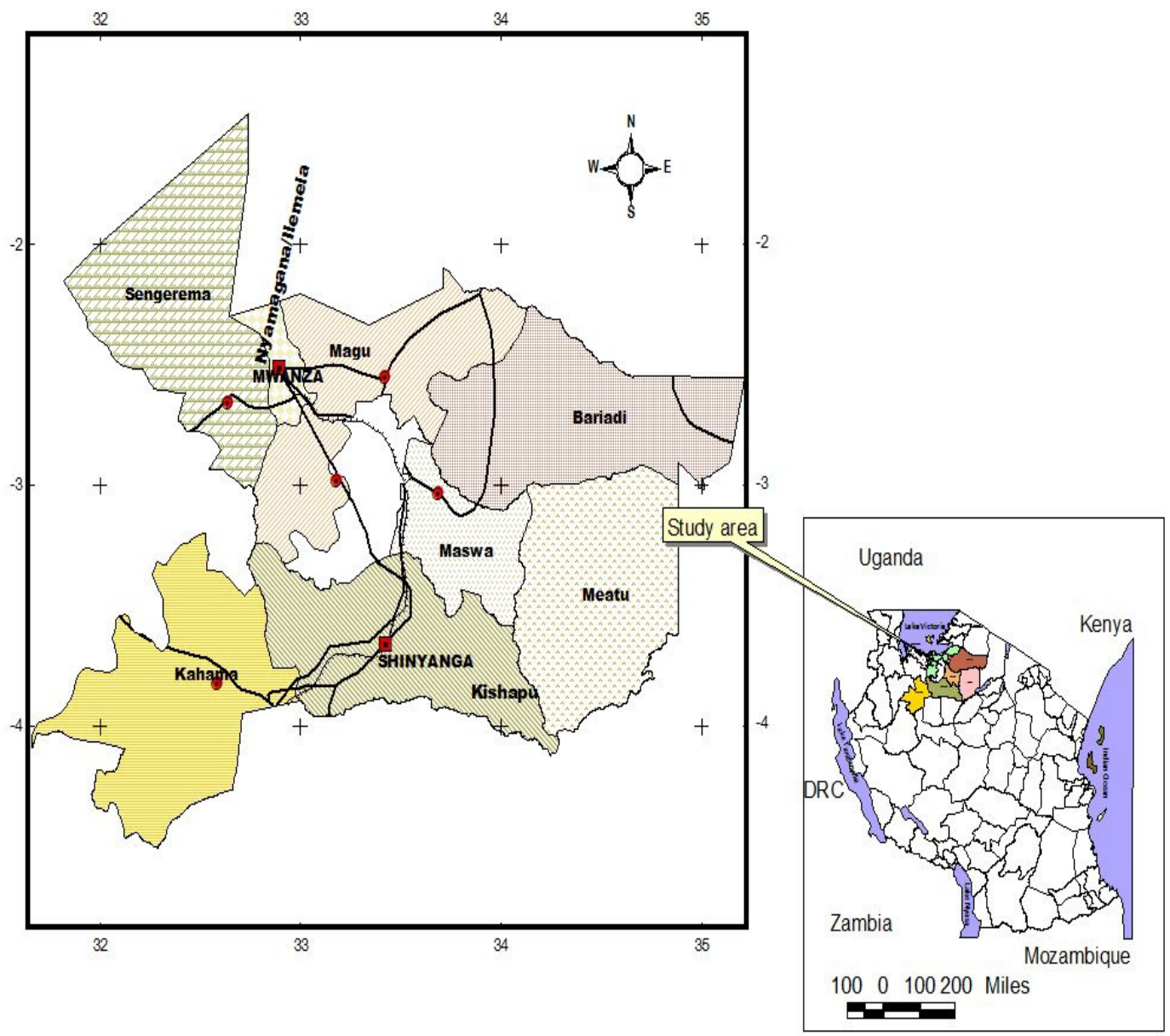

Figure 1. Location of the study area.

Also, they did not keep records of their business. In this regard, a control group of 105 animals were selected from Kahama district and used to determine the Average Daily Gain (ADG) along with 5675 animals (belonging to the respondents) whose weights were tracked during the study period covering 12 to 16 weeks ( 3 to 4 months). The animals under fattening were of the same breed that is Tanzanian short horn zebu (TSHZ) and same fodder conditions originating within the lake zone. Most of them were mature bulls and few culled cows purchased by the respondents from the livestock markets in the lake zone. A weight band tape, which is designed to take the live weight of animals such as; cattle, pigs, sheep and goats was used to measure the live weight of the study animals from each respondent (Figure $2 a$ and b). The tape measure was used in the field because cattle weighing instruments are costly and heavy to transport and it is a practical field techniques, particularly in less developed countries. The animals' heart girth measurements were taken to predict animal's weights at entry, every two weeks thereafter and at exit.

\section{Analytical framework}

Technical efficiency can be estimated using computer software such as LIMDEP econometrics packages (Green, 1993) or the Frontier 4.1 program (Coelli, 1996) to find the maximum likelihood estimates for the parameters of the stochastic frontier production function. The stochastic frontier production function model is popular because of its flexibility and ability to closely marry economic concepts with modeling the reality (Dawang et al., 2011). Battese and Corra, 1997 applied the technique to the pastoral zone of the Eastern Australia.

Recently, many studies have been done in Africa using the technique which include; Facayode et al. (2011), for Technical efficiency analysis on small scale rabbit production in South to West Nigeria, Dawang et al., 2011 used the technique to estimate the profitability and technical efficiency of artisanal fishermen also in Nigeria, while Oleke and Isinika (2008) used the technique to assess the technical efficiency of commercial egg production in Tanzania.

\section{Stochastic frontier production function analysis (SFA)}

Farmers in agricultural production aim at maximizing production, minimizing costs and maximizing profits. However, though every producer may attempt to optimize, not all of them may succeed in their efforts. Given the same inputs and technology, some farmers will produce more efficient than others. Econometrics estimation techniques allow for the fact that deviations of observed choices from optimal ones are due to either failure to optimize (inefficient) or due to random shocks.

The SFA produces efficiency estimates or scores of individual producers, thus identifying those who need interventions and corrective measures. The variations of efficiency scores can be 

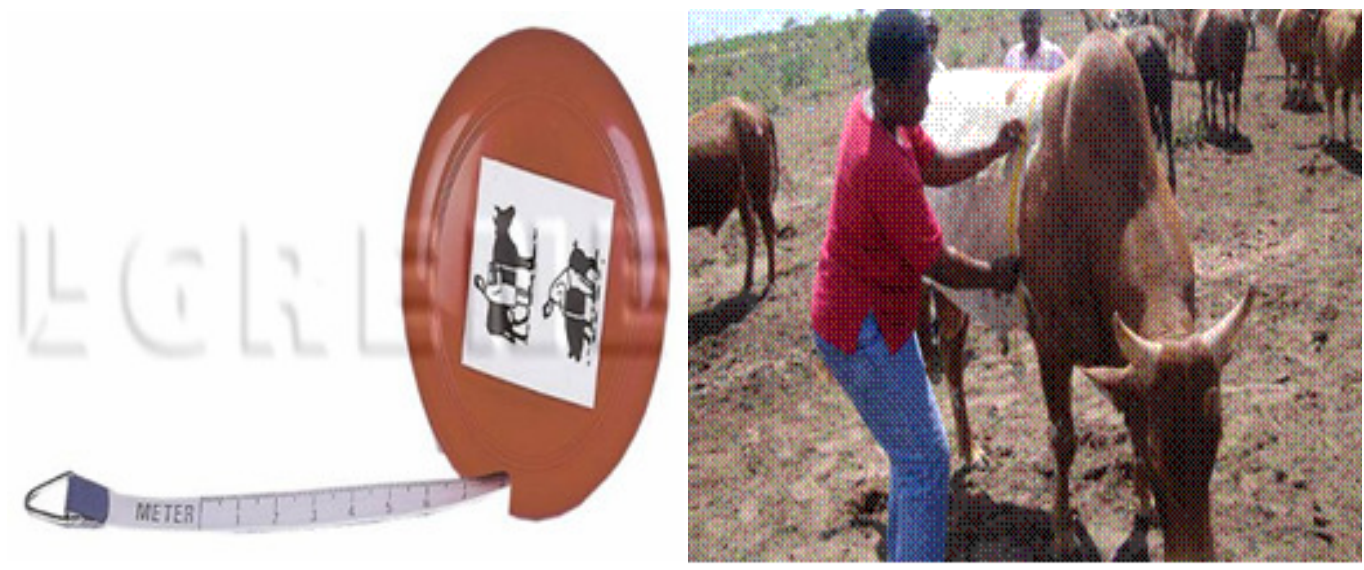

Figure 2. (a) Weight band tape.

(b) Estimating live weight using weight band tape.

related to producer's characteristics like age, size, ownership, location, education etc. Thus one can identify source of inefficiency. The SFA also provides a powerful tool for examining effects of interventions. A stochastic production frontier model using the FRONTIER 4.1 statistical software developed by Coelli (1996) was used to estimate the technical efficiency of beef cattle fattening in the study area. This analysis has the advantage of separating the impact of weather and other factors that contribute to variations in technical efficiency.

A frontier model with output-oriented technical efficiency according to Battese and Coelli (1995) is specified in Equation 1.

$Y_{i}=X_{i} \beta+\left(\varepsilon=v_{i}-\mu\right.$

Where; $Y_{i j}=$ is the (logarithm of) output in terms of weight gain obtained by the $i$-th respondents from the $j^{\text {th }}$ animal (for $i=1,2,3$ $\mathrm{N}$; and $\mathrm{j}=1,2,3, \ldots . \mathrm{m}), \mathrm{X}_{\mathrm{ik}}=$ is the corresponding matrix of $\mathrm{K}$ inputs, $\beta=$ is a $k x 1$ vector of unknown parameter to be estimated, $\varepsilon_{i}$ is the disturbance term comprised of two independent components, $\mathrm{V}_{\mathrm{i}}$ and $\mathrm{U}_{\mathrm{i}}, \mathrm{V}_{\mathrm{i}}=$ are random variables which are assumed to be i.i.d. $N\left(0, \delta^{2} v\right)$, and independent of the $U_{i}$ 's and $U_{i s}$ $=$ are non negative random variables which are assumed to account for technical inefficiency in production and are assumed to be independently distributed as truncations at zero of the $\mathrm{N}\left(\mathrm{m}_{\mathrm{i}}, \delta^{2}{ }_{\mathrm{u}}\right)$.

The maximum likelihood estimation of Equation 1 provides the estimators for $\beta_{j}$ and variance estimators and other relationships denoted as;

$$
\begin{aligned}
& \delta^{2}=\delta_{v}^{2}+\delta_{\mu}^{2} . \\
& \gamma=\delta_{v}^{2} / \delta^{2} \\
& \lambda=\delta_{v}^{2} / \delta_{\mu}^{2} .
\end{aligned}
$$

Where, $\delta^{2}, \delta^{2}{ }_{v}, \delta^{2}{ }_{u}$ are the overall variance of the model, variance of the random error, and variance of the technical inefficiencies respectively. According to Battese and Corra (1997), gamma ( $\mathrm{Y}$ ) is the total output made on the frontier function which is attributed to technical efficiency. The parameter gamma $(\gamma)$ has a value between zero and one. Hence (1- $\gamma$ ) measures the technical inefficiency of the farms. The parameter lambda $(\lambda)$ is expected to be greater than one. This condition according to Facayode et al. (2011) indicates a good fit for the model and correctly specified error term $\left(V_{i}\right.$ and $\left.U_{i}\right)$.

From Equation 1, the polynomial of degree 2 technical efficiency equation for beef cattle fattening in the study area was specified as follows;

$$
\begin{aligned}
& \operatorname{In} Y_{i}=\beta_{o}+\beta_{1} \operatorname{In} X^{+} \beta_{2} \operatorname{In} X_{i}^{+} \beta_{3} \operatorname{In} X_{5}^{+} \beta_{4} \operatorname{In} X^{+} \beta_{12} \operatorname{In} X_{\operatorname{In}} X_{i}^{+} \beta_{13} \operatorname{In} X_{1} \operatorname{In} X_{5} \\
& +\beta_{14} \operatorname{In} X \operatorname{In} X^{+} \beta_{23} \operatorname{In} X \operatorname{In} X^{+} \beta_{24} \operatorname{In} X \operatorname{In} X+\beta_{34} \operatorname{In} X \operatorname{In} X \\
& +1 / 2\left(\beta_{11} \operatorname{In} X_{1}+\beta_{22} \operatorname{In} X_{2}+\beta_{33} \operatorname{In} X_{3}+\beta_{44} \operatorname{In} X_{4}\right)^{2}+\beta_{5} X_{5}+\beta_{6} X_{6} \\
& +\left(\boldsymbol{V}_{i}-\boldsymbol{\mu}\right)
\end{aligned}
$$

Where; In = denotes the natural logarithm (base e), $Y_{i}=$ is the total weight gain over the study period for the $j^{\text {th }}$ animal of the $i^{\text {th }}$ respondent for $\mathrm{I}=1,2,3 \ldots \mathrm{n}$ and for $\mathrm{j}=1,2,3 \ldots \mathrm{k}, \mathrm{X}_{1}=$ Herd size in numbers denoted as HERDSIZE, $X_{2}=$ Supplementary feeds in $\mathrm{kg}$ denoted as FEED, $\mathrm{X}_{3}=$ Treatment index denoted as TREAT, $\mathrm{X}_{4}=$ Minerals index denoted as MINERAL, $X_{5}=$ Location of farmers denoted as LOC (Dummy), $X_{6}=$ Fattening potential according to farmers perception denoted as FATPOT (Dummy) and $\beta_{i j}=A$ vector of parameters to be estimated

\section{Technical inefficiency model}

According to Battese and Coelli (1995) in the efficiency model, the one sided error term is specified as:

$\mu_{i}=\delta_{0}+\sum \delta_{m} Z_{m i}+\omega_{i t}$.

Where; Zs are social economic variables used to explain efficiency differences among beef cattle fatteners, where the parameters $\delta_{m}$ are unknown, to be estimated and $\omega_{\text {it }}$ are iid random variable with zero mean and variance defined by the truncation of the normal distribution. The specific $Z$ variables in the above model can be specified as follows:

$\mathrm{U}_{\mathrm{i}}=\delta_{0}+\sum \Sigma \delta_{\mathrm{ij}} \mathrm{Z}_{\mathrm{ij}}$

Where: $U_{i}=$ the technical inefficiency of the $i^{\text {th }}$ respondent for $i=1$, $2,3, \ldots \ldots, N ; Z_{i j}=$ the $j^{\text {th }}$ socio-economic variable for the $i^{\text {th }}$ respondent for $\mathrm{i}=1,2,3, \ldots, \mathrm{N}$ and $\mathrm{j}=1,2,3, \ldots \ldots \ldots, \mathrm{k} \delta_{0}=$ the intercept, and $\delta_{j}=$ the coefficient for the $\mathrm{K}^{\text {th }}$ variable. 
Table 1. Average daily weight gain per animal.

\begin{tabular}{lccccc}
\hline Variable & Mean & Min & Max. & Std & Mode \\
\hline Duration of fattening (days) & 92 & 60 & 240 & 21.9 & 90 \\
Average weight gain per animal over the study period $(\mathrm{Kg})$ & 58.6 & 37.7 & 151.1 & 13.6 & 56.6 \\
Average daily weight gain per animal $(\mathrm{Kg})$ & 0.646 & 0.236 & 1.259 & 0.116 & 0.630 \\
\hline
\end{tabular}

Source: Field survey data, 2011/2012.

The socio-economic variables represented in this study include; $1=$ age, 2 = educational level in years, 3 = experience, 4 = housing type, $5=$ Ethnic group, $6=$ access to credit and $7=$ extension services. The technical inefficiency in Equation 7 can be estimated if the technical inefficiency effects, $U_{i}$ are stochastic and have particular distributional properties (Battese and Corra, 1997). Under the null hypothesis gamma $(\mathrm{Y})=0$, the stochastic model reduces to a traditional average response function, thus no technical inefficiency effects exist. The null hypothesis was tested using log likelihood ratio test as follows;

$\lambda=-2 \operatorname{In}\left\{L\left(H_{0}\right)\right\}-\operatorname{In}\left\{L\left(H_{i}\right)\right\}$

Where; $L\left(\mathrm{H}_{0}\right)$ and $L\left(\mathrm{H}_{\mathrm{i}}\right)$ are values of likelihood function under the null hypothesis and the alternative $\left(\mathrm{H}_{\mathrm{i}}\right)$ hypothesis, respectively.

\section{RESULTS AND DISCUSSION}

\section{Determination of average daily weight gain (ADG)}

The ADG was calculated by subtracting the initial weight from the final weight and dividing by the number of fattening days. The computed ADG is as shown in Table 1.

The ADG per animal was $0.646 \mathrm{~kg}$ and the mean fattening duration was 92 days. This finding compares well with similar finding by Mwilawa (2012) which revealed that ADG for Boran beef cattle kept under station conditions in Tanzania was $0.889 \mathrm{~kg}$ which implies that traditional beef cattle respond to fattening.

\section{Results of technical efficiency analysis}

Descriptive statistics of variables used for the production function frontier estimation are presented in Table 3 . The mean total animal weight gain per farmer (obtained by multiplying the average daily weight gain per animal $(0.646 \mathrm{~kg} /$ day $)$ with the number of animals per enterprise and the duration of fattening) was $3607.75 \mathrm{~kg}$ with a standard deviation of $4292.2 \mathrm{~kg}$. The large value of standard deviation implies that the beef cattle fattening operators were raising different numbers of animals with a minimum of 4 animals and a maximum of 330 animals.

The mean quantity of supplementary feed used per farmer was $1053.8 \mathrm{~kg}$ with a minimum of 0 and maximum of $7800 \mathrm{~kg}$. There was variability in feed usage by cattle fatteners measured by the minimum and maximum amounts, which was confirmed by the large value of the standard deviation. This may be due to differences in feed ranging from exclusive standing hay to different additional quantities of supplementary feeds. Feed scarcity and the high cost of feeds as it was observed during the survey, making it difficult for most operators to provide adequate feed for speedy weight gain of the animals. This implies that improvement in feed availability in the study area may lead to improvements in animals' weight gain and reduce the duration of beef cattle fattening.

The mean mineral index (calculated as a ratio of feeds) was 0.004 while the mean for the treatment index was 0.32 . The location of the respondent (urban $=1$ or periurban $=0$ ) was included in the model as dummy variable. The fattening potential according to farmers perception of the animals (un-castrated bulls $=1$ or castrated bulls and cows $=0$ ) was also included as a dummy variable to test farmers' preferences to fatten un-castrated beef cattle bulls over castrated bulls and cows as observed during the survey. A summary of all the descriptive statistics is presented in Table 2.

Most of the entrepreneurs who were engaged in beef cattle fattening were middle aged being 39.5 years on average age with a standard deviation of 9.2 years. This shows that most farmers were middle aged people. The average year of schooling was 6.8 years with a minimum of 0 , a maximum of 16 and a standard deviation of 3 years, hence most of the farmers attended at least primary school. The average experience in beef fattening was 5.4 years with a standard deviation of 4.6 years implying that most of the farmers are relatively new in the beef fattening enterprises, but the most experienced operator had been 26 years in the business. Other variables such as the average housing type, credit provision, extension services and ethnic group were included in the model as dummy values.

\section{Results of stochastic frontier production analysis}

Equation 8 was used to test the assumption of the translog model specification for the beef cattle fattening. The maximum likelihood estimates of the stochastic frontier production function are presented in Table 3 . The findings show that, the value of lambda $(\lambda)$ was greater than one (17.36) implying goodness fit for the estimated model and also correct specification of the error term 
Table 2. Descriptive statistics of variables used in the stochastic frontier analysis.

\begin{tabular}{llcccc}
\hline Variable & Notation & Mean & SD & Min & Max \\
\hline Total animal weight gain per farmer $(\mathrm{kg})$ for the study period & WGAIN & 3607.8 & 4292 & 151.1 & 18699 \\
Number of animals per farmer (N) & HERDSIZE & 63.6 & 76 & 4 & 330 \\
Feeds usage (kg) & FEED & 1053.8 & 1214 & 0 & 7800 \\
Treatment (Index) & TREAT & 0.32 & 1.8 & 0 & 16.7 \\
Mineral Intake (Index) & MINERAL & 0.004 & 0.006 & 0 & 0.343 \\
Location & LOC & 0.45 & 0.5 & 0 & 1 \\
Fattening Potential & FATPOT & 0.4 & 0.5 & 0 & 1 \\
Age (years) & AGE & 39.5 & 9.2 & 24 & 69 \\
Education (years) & EDUYRS & 6.8 & 3 & 0 & 16 \\
Experience (years) & EXP & 5.4 & 4.6 & 1 & 26 \\
Housing type & HOUSE & 0.8 & 0.4 & 0 & 1 \\
Credit provision & CREDIT & 0.06 & 0.2 & 0 & 1 \\
Extension services & EXT & 0.6 & 0.5 & 0 & 1 \\
Ethnic group & ETHNIC & 0.8 & 0.4 & 0 & 1 \\
\hline
\end{tabular}

Table 3. Maximum Likelihood estimates of trans-log production function.

\begin{tabular}{|c|c|c|c|c|c|}
\hline Variable & Par. & Expected sign & Coeff. & SE & t-ratio \\
\hline Constant & $\beta_{0}$ & & 4.874 & 0.13 & 37.451 \\
\hline LNHERDSIZE & $\beta_{1}$ & - & $6.036^{*}$ & 3.232 & 1.868 \\
\hline LNFEED & $\beta_{2}$ & + & 1.031 & 1.214 & 0.85 \\
\hline LNMINERAL & $\beta_{3}$ & - & $3.276^{*}$ & 1.895 & -1.729 \\
\hline LNTREAT & $\beta_{4}$ & $+/-$ & $1.758^{*}$ & 1.06 & -1.659 \\
\hline LNHERDSIZE $^{2}$ & $\beta_{5}$ & $+/-$ & $2.581^{*}$ & 1.617 & -1.596 \\
\hline LNFEED $^{2}$ & $\beta_{6}$ & - & -0.613 & 0.608 & -1.009 \\
\hline LNMINERAL $^{2}$ & $\beta_{7}$ & + & $1.637^{\star}$ & 0.949 & 1.724 \\
\hline LNTREAT $^{2}$ & $\beta_{8}$ & + & $0.915^{*}$ & 0.535 & 1.71 \\
\hline LN HERDSIZE X FEED & $\beta_{9}$ & + & $0.093^{\star *}$ & 0.041 & 2.284 \\
\hline LN HERDSIZE X MINERAL & $\beta_{10}$ & + & 0.005 & 0.049 & 0.097 \\
\hline LN HERDSIZE X TREAT & $\beta_{11}$ & - & -0.043 & 0.046 & -0.942 \\
\hline LN FEED X MINERAL & $\beta_{12}$ & $+/-$ & 0.025 & 0.033 & 0.749 \\
\hline LN FEED X TREAT & $\beta_{13}$ & $+/-$ & -0.006 & 0.037 & -0.168 \\
\hline LN MINERAL X TREAT & $\beta_{14}$ & $+/-$ & -0.03 & 0.053 & -0.565 \\
\hline LOCATION & $\beta_{15}$ & $+/-$ & 0.015 & 0.043 & 0.344 \\
\hline FATPOT & $\beta_{16}$ & $+/-$ & 0.033 & 0.038 & 0.867 \\
\hline \multicolumn{6}{|l|}{ Variance parameter } \\
\hline Sigma-squared & $\sigma^{2}$ & & $0.082^{\star * *}$ & 0.026 & 3.154 \\
\hline Gamma & $Y$ & & $0.853^{\star * *}$ & 0.066 & 13.02 \\
\hline log likelihood (LLF) & & & 46.18 & & \\
\hline Lambda & $\lambda$ & & 17.36 & & \\
\hline \multicolumn{6}{|l|}{ Inefficiency effect } \\
\hline AGE & $\delta_{1}$ & - & $-0.044^{\star *}$ & 0.021 & -2.1 \\
\hline $\mathrm{AGE}^{2}$ & $\delta_{2}$ & $+/-$ & $0^{*}$ & 0 & 1.97 \\
\hline EDUC & $\delta_{3}$ & - & $0.314^{* * *}$ & 0.09 & 3.485 \\
\hline EDUC $^{2}$ & $\delta_{4}$ & - & $-0.02^{\star \star \star}$ & 0.006 & -3.542 \\
\hline EXP & $\delta_{5}$ & - & $-0.073^{*}$ & 0.04 & -1.814 \\
\hline $\mathrm{EXP}^{2}$ & $\delta_{6}$ & $+/-$ & $0.004^{*}$ & 0.002 & 1.83 \\
\hline
\end{tabular}


Table 3. Contd

\begin{tabular}{llcccc}
\hline HOUSING & $\delta_{7}$ & $+/-$ & 0.085 & 0.155 & 0.549 \\
CREDIT & $\delta_{8}$ & - & -0.104 & 0.14 & -0.746 \\
EXTENSION & $\delta_{9}$ & - & $-0.366^{* *}$ & 0.153 & -2.387 \\
ETHNIC & $\delta_{10}$ & - & $0.531^{* * *}$ & 0.173 & -3.068 \\
\hline
\end{tabular}

Level of Significance; ${ }^{* *} \alpha=0.01 ;{ }^{* *} \alpha=0.05 ;{ }^{*} \alpha=0.1$

distribution. This was also evident from the estimated Gamma $(Y)$ value of 0.853 which measures the level of inefficiency of the production system, this was significant at $\alpha=0.05$ and was above the 50 percent of a unity. These results imply that within the study area, about $85.3 \%$ of the variation in beef cattle fattening is explained by inefficiency, whereas the remaining $14.7 \%$ (that is $1-Y$ $=0.147$ ) is due to measurement error and specifications bias as well as other factors that are not incorporated in the stochastic frontier and inefficiency effects models. This further confirms that the technical inefficiency effects are significant in the estimated model. The variance parameter $\left(\sigma^{2}\right)$ was also positive $(0.082)$ and significantly greater than zero at $\alpha=0.05$.

\section{The inefficiency model estimates}

The inefficiency analysis of the stochastic frontier indicated the coefficients for age, education ${ }^{2}$, experience; extension contact and ethnic group were all negative and significantly different from zero, suggesting that increasing these variables will increase technical efficiency. However, ageing $\left(\mathrm{age}^{2}\right)$ does not contribute to technical efficiency such that the coefficient for this variable is zero. The estimated coefficient on education is positive and significantly greater than zero indicating increase in production inefficiency. However, as the education level increases (Education ${ }^{2}$ ) the effect on technical efficiency is negative and statistically significant indicating reduction in production inefficiency. In other words, education (years of schooling) had a positive correlation with technical efficiency. These results are consistent with Ogunniyi (2011) and Dawing et al. (2011) who established that for every extra year of schooling that a farmer/fisher got, there was an increase in the chance or probability of being technically efficient.

The estimated coefficient on experience is negative and statistically significantly different from zero, contributing to decrease in technical inefficiency by $7.3 \%$ for every year of increase in experience. Credit access showed a negative relationship with technical inefficiency as expected though it was not significant implying that only few farmers had access to credit. Having access to credit reduced the level of inefficiency of respondents by $1.04 \%$. This means policies that will make micro-credit from government and non-governmental agencies accessible to these farmers will go a long way to address their resource use inefficiency problems. The coefficient for extension service contact was negative and significantly different from zero indicating that if a respondent had contact with extension services they were likely to experience increase in technical efficiency equivalent to about $3.66 \%$ average daily weight gain of the fattening animals. The Ethnic group was negative and significant $(\alpha<0.05)$ indicating that Sukuma group (denoted as 1) were more involved in beef cattle fattening compared to other ethnic groups (denoted by zero).

\section{Technical efficiency score analysis}

The frequency distributions of technical efficiency (TE) scores are presented in Table 4 . The findings show the beef fattening enterprises achieved on average $91 \%$ level of efficiency, ranging from 48 to $98 \%$ with a wide range of efficiency variation among the operators (Appendix 1). About $81.6 \%$ of beef cattle fattening operators operate at $91 \%$ TE or more while $13.8 \%$ were able to achieve $81 \%$ up to $90 \%$ TE levels. The results also suggest that about $98.7 \%$ of the respondents were able to achieve above $50 \%$ of the technical efficiency. Only $1.1 \%$ of the enterprises operated at $50 \%$ or less (Appendix 1). These results suggest that the majority of the respondents operate efficiently though not at $100 \%$, there is still room for improving technical efficiency of few beef cattle fattening enterprises in the study area.

\section{CONCLUSION AND RECOMMENDATIONS}

This study applied the stochastic frontier model to estimate technical efficiency of beef cattle fattening. Results give efficiency scores that range from 48 to $98 \%$, suggesting that there is room for improving the low performing cattle fattening enterprises. Further, it was found that education, experience, access to credit, extension services and ethnicity of cattle fattening operator contribute negatively to inefficiency that is, positively to efficiency improvement in cattle fattening. On the other hand, location and housing type did not have a positive influence on efficiency in cattle fattening, probably indicating that these variables did not render any technological differences among the cattle fattening entrepreneurs in the study area. All these findings have important implications on improving beef fattening 
Table 4. Technical Efficiency scores for the sampled beef cattle operators.

\begin{tabular}{ccc}
\hline Technical efficiency level (\%) & No. of farmers & Percentage \\
\hline$<50$ & 1 & 1.1 \\
$51-60$ & 1 & 1.1 \\
$61-70$ & 1 & 1.1 \\
$71-80$ & 1 & 1.1 \\
$81-90$ & 12 & 13.8 \\
$>91$ & 71 & 81.6 \\
Total & 87 & 100 \\
Mean & 0.91 & \\
Standard Deviation & 0.08 & \\
Minimum & 0.48 & \\
Maximum & 0.98 & \\
\hline
\end{tabular}

efficiency in Tanzania. The positive relationship of education and extension on technical efficiency imply providing appropriate knowledge and skills would facilitate better use of the available cattle fattening technologies by the operators who are currently operating inefficiently. Necessary interventions would include improving fattening operators' knowledge on feeding and disease control methods.

The negative relationship between access to credit and inefficiency implies that policies that will improve access to credit from government and non government agencies would increase the cattle fattening operators' ability to acquire better technologies (better cattle breeds and feeds through acquisition of mini to medium ranches where pastures could be improved and herd size expanded) with the potential of increasing productivity for domestic and export market. The efforts by the government to establish an agricultural bank is likely going to improve access to credit by farmers in Tanzania including cattle fattening operators if the bank conditions for credit will be favorable. These findings can be used by the Ministry of Livestock and Fisheries Development extension agents to promote beef cattle fattening in areas where beef cattle fattening is not practiced in the country.

\section{ACKNOWLEDGEMENT}

The authors are grateful to the livestock farmers in the study areas of Mwanza and Shinyanga regions for sparing their time during survey and questionnaire administration and to the permanent secretary, Ministry of Livestock and Fisheries Development for financial support through ASDP programme.

\section{REFERENCES}

Abu O, Asember DJ (2011). Opportunities for smallholder spinach farmers in Nigeria; A profit efficiency analysis. J. Econ. 2(2):75-79.

Battese GE, Corra GS (1997). Estimation of a Production Function
Model with Applied to the Pastoral zone of Eastern Australia. Aust. J. Agric. Econ. 21:169-179.

Battese GE, Coelli TJ (1995). A model for technical inefficiency effect in Stochastic Frontier production for panel data. Empirical Econ. 20:325-345.

Boris E, Bravo-Ureta and Antonio EP (1997). Technical, Economic, and Allocative efficiency in peasant farming. Evidence from the Dominican Republic. Dev. Econ. 35(1):48-67.

Bravo-Ureta BE, Rieger L (1991). Dairy farm efficiency measurement using stochastic frontier and neo-clssical duality. Am. J. Agric. Econ. 73:421-428.

Coelli TJ, (1996). A guide to FRONTIER Version 4.1. A computer program for Stochastic Frontier Production and Cost Function Estimation. Centre for Efficiency and Productivity Analysis (CEPA) Working Papers. Dept. of Econometrics University of New England, Armidale, NSW 2351, Australia. http://www.une.edu.au/econometrics/cepawp.htm.

Dawang NC, Ayuba D, Matawal OM (2011). Estimates of profitability and Technical Efficiency of Artisanal Fisheries. A case study of Natural Lakes from Plateau State Nigeria. Asian J. Agric. Sci. 3(6):516-523.

Effiong EO, Onyenweaku CE (2006). Profit efficiency in Bloiler production in Akwa Ibom State, Nigeria. Department of Agricultural economics, Michael Okpara University of Agriculture, Umudike, Umuakwa, Abia State, Nigeria. Int. J. Agric. Rural Dev. 7(1):72-79.

Facayode SB, Rahji MAY, Fayeye TR Yinusa SO (2011). Technical Efficiency of Small Scale Rabit Production in South-West, Nigeria. J. Agric. Res. Dev. 10(1).

FAO (Food and Agriculture Organization of the United Nations) (2005). The State of food and Agriculture, Livestock Balance. Produced by the Electronic Publishing Policy and Support Branch. Communication Division.

Green WH (1993). Limdep Version 8.0 Econometric Modeling Guide. Econometric Software, Inc, Plainview, New York. P. 201.

MLD (Ministry of Livestock Development) (2006). National Livestock Policy (NLP). http://www.mifugo.go.tz/

MLFD (Ministry of Livestock and Fisheries Development) (2010). Livestock Sector Development Strategy. Government document.

MLFD (Ministry of Livestock and Fisheries Development) (2011). Livestock Sector Development Program. Government document.

MLFD (Ministry of Livestock and Fisheries Development) (2012). Budget speech 2012/13. http://www.mifugo.go.tz/

Mwilawa AJ (2012). Effects of Different Diets on Weight Gain, Carcass and Meat Quality Characteristics of two Indigenous Cattle Breeds of Tanzania. A Thesis Submitted in Partial Fulfilment of the Degree of Doctor of Philosophy of Sokoine University of Agriculture. P. 245.

Ogunniyi LT (2011). Profit Efficiency among maize producers in Oyo State, Nigeria. ARPN J. Agric. Biol. Sci. pp. 11-17.

Oleke JM, Isinika AC (2008). Assessing the technical efficiency of Commercial egg production in Tanzania for improved livelihoods. J. 
Dev. Agric. Econ. 3(8):343-352.

Otieno DJ, Hubbard L, Ruto E (2012). Determinants of Technical Efficincy in beef cattle production in Kenya. Selected paper prepared for presentation at the International Association of Agricultural Economist (IAAE) Triennial Conference, Foz do Iguacu, Brazil.

URT (United Republic of Tanzania) (2011). The Economic Survey 2010. Government document produced by the Ministry of Finance. Dar es Salaam, Tanzania.
URT (United Republic of Tanzania) (2011). Agriculture and Food Security Investment Plan (TAFSP) 2011-12 to 2020-21. Main Document. 
Appendix 1. beef cattle fattening operators individual efficiency score

\begin{tabular}{|c|c|c|}
\hline Beef Cattle fattening operators No. & Efficiency score & Percentage \\
\hline 1 & 0.96214561 & 96.21 \\
\hline 2 & 0.94622229 & 94.62 \\
\hline 3 & 0.90990675 & 90.99 \\
\hline 4 & 0.90836731 & 90.84 \\
\hline 5 & 0.91718459 & 91.72 \\
\hline 6 & 0.94651977 & 94.65 \\
\hline 7 & 0.92162874 & 92.16 \\
\hline 8 & 0.91154839 & 91.15 \\
\hline 9 & 0.92729179 & 92.73 \\
\hline 10 & 0.94453186 & 94.45 \\
\hline 11 & 0.9178525 & 91.79 \\
\hline 12 & 0.95143245 & 95.14 \\
\hline 13 & 0.95393396 & 95.39 \\
\hline 14 & 0.95476767 & 95.48 \\
\hline 15 & 0.91568868 & 91.57 \\
\hline 16 & 0.90804903 & 90.8 \\
\hline 17 & 0.93534417 & 93.53 \\
\hline 18 & 0.9089111 & 90.89 \\
\hline 19 & 0.97801878 & 97.8 \\
\hline 20 & 0.93575987 & 93.58 \\
\hline 21 & 0.9321321 & 93.21 \\
\hline 22 & 0.91532701 & 91.53 \\
\hline 23 & 0.9009158 & 90.09 \\
\hline 24 & 0.90640892 & 90.64 \\
\hline 25 & 0.93834282 & 93.83 \\
\hline 26 & 0.95582983 & 95.58 \\
\hline 27 & 0.94903479 & 94.9 \\
\hline 28 & 0.92827808 & 92.83 \\
\hline 29 & 0.84726318 & 84.73 \\
\hline 30 & 0.97484628 & 97.48 \\
\hline 31 & 0.96947349 & 96.95 \\
\hline 32 & 0.90510863 & 90.51 \\
\hline 33 & 0.93306386 & 93.31 \\
\hline 34 & 0.63422246 & 63.42 \\
\hline 35 & 0.96445711 & 96.45 \\
\hline 36 & 0.91327269 & 91.33 \\
\hline 37 & 0.83504685 & 83.5 \\
\hline 38 & 0.95367473 & 95.37 \\
\hline 39 & 0.91304118 & 91.3 \\
\hline 40 & 0.9195629 & 91.96 \\
\hline 41 & 0.96544705 & 96.54 \\
\hline 42 & 0.92534497 & 92.53 \\
\hline 43 & 0.96375558 & 96.38 \\
\hline 44 & 0.92175427 & 92.18 \\
\hline 45 & 0.95109311 & 95.11 \\
\hline 46 & 0.93799274 & 93.8 \\
\hline 47 & 0.96986503 & 96.99 \\
\hline 48 & 0.89269371 & 89.27 \\
\hline 49 & 0.90672046 & 90.67 \\
\hline 50 & 0.94312793 & 94.31 \\
\hline 51 & 0.95021185 & 95.02 \\
\hline
\end{tabular}


Mlote et al. 207

\section{Appendix 1}

\begin{tabular}{|c|c|c|}
\hline 52 & 0.91480716 & 91.48 \\
\hline 53 & 0.87264073 & 87.26 \\
\hline 54 & 0.9002228 & 90.02 \\
\hline 55 & 0.96420636 & 96.42 \\
\hline 56 & 0.94762449 & 94.76 \\
\hline 57 & 0.96078686 & 96.08 \\
\hline 58 & 0.95389044 & 95.39 \\
\hline 59 & 0.9462963 & 94.63 \\
\hline 60 & 0.91920711 & 91.92 \\
\hline 61 & 0.93534727 & 93.53 \\
\hline 62 & 0.94473073 & 94.47 \\
\hline 63 & 0.92517926 & 92.52 \\
\hline 64 & 0.9157181 & 91.57 \\
\hline 65 & 0.89907558 & 89.91 \\
\hline 66 & 0.95832715 & 95.83 \\
\hline 67 & 0.90969569 & 90.97 \\
\hline 68 & 0.90579944 & 90.58 \\
\hline 69 & 0.92821406 & 92.82 \\
\hline 70 & 0.85060658 & 85.06 \\
\hline 71 & 0.95608835 & 95.61 \\
\hline 72 & 0.94071958 & 94.07 \\
\hline 73 & 0.88981 & 88.98 \\
\hline 74 & 0.94438271 & 94.44 \\
\hline 75 & 0.86631765 & 86.63 \\
\hline 76 & 0.91320091 & 91.32 \\
\hline 77 & 0.97630442 & 97.63 \\
\hline 78 & 0.52971188 & 52.97 \\
\hline 79 & 0.963581 & 96.36 \\
\hline 80 & 0.47609183 & $47.61^{\star *}$ \\
\hline 81 & 0.93853943 & 93.85 \\
\hline 82 & 0.93368394 & 93.37 \\
\hline 83 & 0.74611235 & 74.61 \\
\hline 84 & 0.92489804 & 92.49 \\
\hline 85 & 0.91071263 & 91.07 \\
\hline 86 & 0.9428072 & 94.28 \\
\hline 87 & 0.82394518 & 82.39 \\
\hline
\end{tabular}

**Below 50\%. 